\title{
Consensus diagnostic criteria and monitoring of twin anemia polycythemia sequence: a Delphi procedure
}

\author{
Asma Khalili1,2, Sanne Gordijn ${ }^{3}$, Wessel Ganzevoort ${ }^{4}$, Basky Thilaganathan ${ }^{1,2}$, Anthony \\ Johnson ${ }^{5}$, Ahmet Baschat ${ }^{6}$, Kurt Hecher ${ }^{7}$, Keith Reed ${ }^{8}$, Liesbeth Lewi ${ }^{9}$, Jan Deprest ${ }^{8}$, Dick \\ Oepkes $^{10}$, Enrico Lopriore ${ }^{10}$
}

\author{
${ }^{1}$ Fetal Medicine Unit, St George's Hospital, St George's University of London, Cranmer \\ Terrace, London SW17 ORE, United Kingdom \\ ${ }^{2}$ Molecular and Clinical Sciences Research Institute, St George's University of London \\ ${ }^{3}$ Department of Obstetrics and Gynecology, University Medical Center Groningen, University \\ of Groningen, Groningen, Netherlands \\ ${ }^{4}$ Department of Obstetrics and Gynecology, Academic Medical Center Amsterdam, \\ University of Amsterdam, Amsterdam, Netherlands. \\ ${ }^{5}$ Departments of Obstetrics/Gynecology \& Pediatric Surgery, The University of Texas Health \\ Science Center, The Fetal Center, Children's Memorial Hermann Hospital, Houston, Texas, \\ The United States of America \\ ${ }^{6}$ The Johns Hopkins Center for Fetal Therapy, Baltimore, Maryland, USA \\ ${ }^{7}$ Department of Obstetrics and Fetal Medicine, University Medical Center Hamburg- \\ Eppendorf, Hamburg, Germany \\ ${ }^{8}$ Twin and Multiple Births Association (TAMBA), UK \\ ${ }^{9}$ Department of Obstetrics and Gynaecology, University Hospitals Leuven; Department of \\ Development and Regeneration, KU Leuven, Belgium \\ ${ }^{10}$ Division of Fetal Medicine, Department of Obstetrics, Leiden University Medical Center, \\ Leiden, The Netherlands
}

\section{Corresponding author:}

Professor Asma Khalil

Fetal Maternal Medicine Unit

St George's University of London

London SW17 ORE

E-mail: akhalil@sgul.ac.uk; asmakhalil79@googlemail.com

Short title: Diagnostic criteria TAPS twins

Key words: twin anemia polycythemia sequence, TAPS, diagnostic criteria, monitoring, twin, multiple pregnancy

This article has been accepted for publication and undergone full peer review but has not been through the copyediting, typesetting, pagination and proofreading process which may lead to differences between this version and the Version of Record. Please cite this article as doi: $10.1002 /$ uog. 21882 


\section{CONRIBUTION}

\section{What are the novel findings of this work?}

Consensus-based antenatal and postnatal diagnostic criteria of Twin anemia polycythemia sequence (TAPS), as well as cut-off values for the parameters involved, monitoring interval and perinatal and long-term survival outcomes were agreed upon by a panel of experts. There was no agreement on the indication for intervention or optimal management.

\section{What are the clinical implications of this work?}

The findings have the potential to change the way clinicians and researchers diagnose TAPS. The inclusion of the middle cerebral artery (MCA) peak systolic velocity (PSV) discordance to the pre-existing MCA PSV criterion is likely to be a significant change in clinical practice as it is likely to identify more TAPS cases. 


\section{ABSTRACT}

OBJECTIVES: Twin anemia polycythemia sequence (TAPS) is associated with increased perinatal mortality and morbidity. Inconsistencies in the diagnostic criteria for TAPS exist, which hinder the ability to establish robust evidence-based management or monitoring protocols. The main aim of this study was to determine, by expert consensus using a Delphi procedure, the key diagnostic features and optimal monitoring approach for TAPS.

METHODS: A Delphi process was conducted among an international panel of experts. Panel members were provided with a list of literature-based parameters for diagnosing and monitoring TAPS. They were asked to rate their importance on a five-point Likert scale. Consensus was sought to determine the cut-off values for accepted parameters, as well as parameters used in the monitoring and assessment of outcome of twin pregnancy complicated by TAPS.

RESULTS: A total of 132 experts were approached, 50 joined the first round; of whom 33 (66\%) completed all three rounds. There was agreement that the monitoring interval for the development of TAPS should be every 2 weeks and that the severity should be assessed antenatally using a classification system based on the middle cerebral artery (MCA) peak systolic velocity (PSV), but no agreement on the gestation at which to start. Once the diagnosis is made, monitoring should be scheduled weekly. For the diagnosis of TAPS, the combination of MCA PSV $\geq 1.5 \mathrm{MoM}$ in the anemic twin and $\leq 0.8 \mathrm{MoM}$ in the polycythemic twin was agreed. Alternatively, MCA PSV discordance $\geq 1 \mathrm{MoM}$ can be used to diagnose TAPS. Postnatally, hemoglobin difference $\geq 8 \mathrm{~g} / \mathrm{dL}$ and inter-twin reticulocyte ratio $\geq 1.7$ were agreed criteria. There was no agreement on the cut-off of the MCA PSV or its discordance for prenatal intervention. The panel agreed on prioritising perinatal and longterm survival outcomes in follow-up studies.

CONCLUSIONS: Consensus-based diagnostic features of TAPS, as well as cut-off values for the parameters involved, were agreed upon by a panel of experts. Future studies are needed to validate these diagnostic features before they can be used in clinical trials of interventions. 


\section{INTRODUCTION}

Twin Anemia Polycythemia Sequence (TAPS) is defined as the presence of anemia in the donor twin and polycythemia in the recipient twin in monochorionic pregnancies, and is associated with increased risk of perinatal mortality and morbidity. ${ }^{1}$ It was first described following Laser surgery for twin to twin transfusion syndrome (TTTS) in 2006 by Robyr et $\mathrm{al}^{2}$, while its spontaneous onset was first described in 2007 by Lopriore et al. ${ }^{3}$ In fact, the copresence of an anemic and polycythemic neonate in twin pregnancy was reported back in the 17 th century ${ }^{4}$; however, it was not identified as TAPS until the $21^{\text {th }}$ century. ${ }^{3}$

The ISUOG twin guideline recommends monitoring for the development of TAPS in all monochorionic twin pregnancies from 20 weeks' gestation, and in particular those pregnancies which were complicated by TTTS and were treated by fetoscopic laser surgery, using ultrasound assessment of the middle cerebral artery (MCA) peak systolic velocity (PSV) every two weeks. ${ }^{5}$ However, there is large variation in clinical practice in ultrasound monitoring for TAPS, probably largely as a result of the lack of robust evidence on the accuracy of diagnostic criteria, natural history and management of the twin pregnancies complicated by TAPS. One third of the Maternal-Fetal Medicine specialists in the United States do not routinely perform MCA PSV in twin pregnancies. ${ }^{6}$ Furthermore, some national guidelines, such as those of the Society for Maternal-Fetal Medicine (SMFM), have not recommended monitoring for TAPS in view of the lack of evidence such monitoring with MCA PSV Doppler improves perinatal outcomes. ${ }^{7}$ Moreover, recent studies have reported that delta MCA-PSV >0.5 multiples of median (MoM) could have greater diagnostic accuracy for predicting TAPS compared to the current MCA-PSV cut-off criteria, and that the fetal intertwin MCA-PSV MoM difference is a good predictor of neonatal intertwin hemoglobin concentration difference and potentially of TAPS. ${ }^{8,9}$

The incidence, as well the natural history, of TAPS is likely to vary according to whether the diagnostic criteria rely only on the presence of MCA PSV $>1.5 \mathrm{MoM}$ in the donor twin and MCA PSV <1.0MoM in the recipient or the delta MCA-PSV, even with normal MCA-PSV values in the donor or recipient twins. Furthermore, the incidence is also likely to vary according to the inter-twin MCA PSV discordance threshold used. 
Inconsistences amongst clinicians and researchers with regards to the diagnostic criteria used for the definition of TAPS are likely to yield further confusion, difficulty in comparing studies, combining the data in a meta-analysis or establishing robust evidence-based management or monitoring pathways. In order to attempt to improve the outcomes of these pregnancies, it is imperative that researchers and clinicians first agree a standard definition. The main aim of this study was to reach expert consensus on the diagnostic criteria of TAPS, using a Delphi methodology. We also attempted to reach expert consensus on the parameters involved in the monitoring of these pregnancies, and those representing the key pregnancy outcomes. 


\section{METHODS}

We applied the Delphi methodology as it is a well-established instrument to reach consensus from a panel of experts for research questions that cannot be answered with empirical evidence and complete certainty. ${ }^{10}$ The Delphi methodology aims to refine the opinions of participating experts, while minimizing confounding factors present in other group response methods. ${ }^{11}$ It is based on the scoring of a series of structured statements that are revised, fed back to the participants and repeated in multiple rounds, in increasing detail, until consensus has been reached. ${ }^{12}$

We identified panel members based on their publication record as lead or senior authors in studies of TAPS, or by suggestion of confirmed panel members. When inviting panel members, we specifically sought wide geographic representation in order to ensure generalizability of the consensus definitions. The votes of all panel members are weighed equally within the Delphi process. Experts who did not complete a particular round were not invited for subsequent rounds. The results were reported according to the guidelines for reporting reliability and agreement studies (GRRAS)..$^{13}$

Data collection

Data were collected in three consecutive rounds between November 2018 and April 2019 by online questionnaires that were presented to panelists through a unique token-secured link for each round. Responses were captured in Limesurvey version 2.50. Non-responders received reminder emails after two and four weeks, and were excluded from subsequent survey rounds if no response was obtained. Each round included the option of offering additional items or suggestions, as well as withdrawal of items from the procedure. Newly suggested items were categorized and carefully considered by the panel for their applicability in this procedure. Details were collected regarding the countries where the experts practise, self-reported expertise, the invasive procedures they perform and the annual average number of dichorionic and monochorionic twins delivering at their hospitals/institutions. 
Based on a literature review, parameters that could potentially be included in the diagnosis, screening, monitoring, and assessment of pregnancy outcomes were presented to the panel for agreement. The panel was also given the opportunity to suggest additional parameters that they considered relevant. Some of the included parameters were not specific for the diagnosis of TAPS, but reflect the possible need to exclude other pathologies, such as TTTS. The panel was asked to rate the literature-based parameters for TAPS on a 5-point Likert-scale ( 1 = very unimportant, $2=$ unimportant, $3=$ neutral, $4=$ important, $5=$ extremely important). The predefined cut-off for inclusion of parameters in the consensus-based diagnostic criteria for TAPS was a median score of 5 on the Likert-scale.

\section{Second round}

In the second round, accepted and newly recommended items from the first round were presented to the panel with the answer options 'yes' or 'no'. Items that in first round had scored the predefined cut-off of a median Likert score of 5 were considered as inclusions and presented to the panel for verification for inclusion, while items with a median score of 4 were presented to verify exclusion. Items with a median score of 3 or lower were considered rejected and verification of rejection was requested. A predefined cut-off level of $70 \%$ agreement was used to define consensus for these questions. In the third round, parameters that fell within a $60-70 \%$ agreement range were presented to the panel for re-consideration.

\section{Third round}

In the third round, parameters with a median score of 5 were presented to define whether the parameter should be a solitary and/or a contributory parameter. A solitary parameter was defined as one sufficient to diagnose TAPS, even if all other parameters are normal. A contributory parameter was defined as one that would require other abnormal parameter(s) to be present to diagnose TAPS. Furthermore, the panel was asked to specify cut-off values for each parameter. The proposed cut-off values were literature based. Experts were also 
asked to determine these cut-offs for solitary or contributory parameters separately, as these thresholds could potentially differ.

This article is protected by copyright. All rights reserved. 


\section{RESULTS}

We invited 132 publishing experts to join this Delphi procedure. In the first round an expert panel of $50(38 \%)$ participants joined, of whom $33(66 \%)$ completed the entire Delphi procedure. Response rates were $74 \%(37 / 50)$ in the second round and $89 \%(33 / 37)$ in the third round. Thus, 66\% (33/50) of participants starting the Delphi finished the complete procedure. Details regarding the self-reported expertise, specialization and demographic characteristics of the participants are shown in Table 1. A list of the experts is included as supplementary material.

In the first round we presented 98 parameters to the panel (Supplementary Table 1). Figures 1 and 2, and Supplementary Figures 1-3 demonstrate the Likert scores of each parameter included in the diagnostic criteria, screening, monitoring and outcome of twin pregnancies complicated by TAPS. All the parameters suggested by members of the expert panel were presented in the following round for voting.

In the third round, the panel agreed the cut-off values for the diagnostic parameters. For the diagnosis of TAPS, the combination of MCA PSV $\geq 1.5 \mathrm{MoM}$ in the anemic twin and $\leq$ $0.8 \mathrm{MoM}$ in the polycythemic twin was agreed. Alternatively, intertwin MCA PSV discordance can also be used to diagnose TAPS (Figure 3). The optimal threshold for MCA PSV discordance was agreed to be $\geq 0.5 \mathrm{MoM}$ by $49 \%$ (16/33) of the experts and $\geq 1.0 \mathrm{MoM}$ by $33 \%$ (11/33). Therefore, $>80 \%$ voted for intertwin MCA PSV discordance $\geq 1.0 \mathrm{MoM}$. Postnatally, hemoglobin difference $\geq 8 \mathrm{~g} / \mathrm{dL}$ and inter-twin reticulocyte ratio $\geq 1.7$ were agreed (Figure 3). There was no agreement on the cut-off of the MCA PSV or its discordance for prenatal intervention. There was agreement that the monitoring interval for the development of TAPS should be 2 weeks and that the severity should be assessed antenatally using a classification system according to MCA PSV, but no agreement on the gestation when to start. Once the diagnosis is made, monitoring should be scheduled weekly.

Table 2 lists the agreed parameters for the definition, screening, monitoring and outcome of twin pregnancies complicated by TAPS. The important parameters during this monitoring were fetal Dopplers and signs of fetal hydrops. The important parameters to consider during the monitoring of TAPS were the MCA PSV in each twin and its discordance, evidence of 
cardiac compromise, signs of fetal hydrops, gestational age at first diagnosis and at assessment (Table 2). The parameters to include in the postnatal assessment and follow-up included the gestational age at birth, hemoglobin level, reticulocyte count, need for transfusion/exchange transfusion, brain abnormalities detected on ultrasound or MRI, limb thrombosis, and long-term assessment of the twins. Consensus was also reached on the rejection of 55 parameters (Supplementary Table 2). 


\section{DISCUSSION}

Summary of the study findings

In this study, consensus based diagnostic criteria for TAPS were established through a Delphi procedure. The combination of MCA PSV $\geq 1.5 \mathrm{MoM}$ in the anemic twin and $\leq$ $0.8 \mathrm{MoM}$ in the polycythemic twin was agreed. Alternatively, MCA PSV discordance $\geq 1 \mathrm{MoM}$ can be used to diagnose TAPS. The postnatal diagnostic criteria included inter-twin hemoglobin difference $>8 \mathrm{~g} / \mathrm{dL}$ and reticulocyte ratio $>1.7$ (Figure 3).

There was agreement that monitoring for TAPS should be scheduled every two weeks and that the severity should be assessed using an antenatal classification system according to the MCA PSV. The panel reached consensus on a number of parameters that are important during the monitoring and postnatal follow-up of these pregnancies (Table 2).

Interpretation of the study findings

The incidence of TAPS varies in the literature, but it is reported to affect $2-5 \%$ of otherwise uncomplicated monochorionic twin pregnancies and $3-16 \%$ of pregnancies complicated by TTTS treated by laser surgery. 1,4,14-17 These estimates are based on the original diagnostic criteria of MCA PSV $>1.5 \mathrm{MoM}$ in the donor and MCA PSV $<0.8 \mathrm{MoM}$ in the recipient twin. It is very likely that the incidence would increase if the recent diagnostic criteria of MCA PSV discordance, even in the presence of MCA PSV within the normal range in either twin, were employed. ${ }^{8,9}$

We noted similar parameters for the diagnosis and screening of TAPS, but with lower cutoffs for screening than diagnosis. In fact, screening in this context actually refers to monitoring using MCA Doppler PSV for the development of the disorder, so the parameters to consider are the same as the diagnostic criteria. The World Health Organization (WHO) defines screening as "the presumptive identification of unrecognized disease in an apparently healthy, asymptomatic population by means of tests, examinations or other 
procedures that can be applied rapidly and easily to the target population". There are no established screening markers that could identify those pregnancies prior to its clinical onset.

\section{Clinical and research implications}

It is important to realise that the performance of the antenatal diagnostic criteria for the postnatal diagnosis of TAPS is not $100 \%{ }^{8}$ According to the most recent studies, the sensitivity and specificity of the cut-off MCA-PSV values (donor $>1.5 \mathrm{MoM}$, recipient $<1.0$ MoM) to predict TAPS are $46 \%$ and $100 \%$, respectively, while the positive predictive value (PPV) and negative predictive value (NPV) are 100\% and 70\%, respectively. Fishel-Bartal et al. have demonstrated that monochorionic twins diagnosed with polycythemia at birth often had MCA-PSV values >1.0 MoM prior to delivery, and therefore they questioned the accuracy of this cut-off. ${ }^{14}$ Furthermore, they reported a strong correlation between delta MCA-PSV and the inter-twin hematocrit difference. ${ }^{14}$ Interestingly, delta MCA-PSV > $0.5 \mathrm{MoM}$ has sensitivity and specificity of $83 \%$ and $100 \%$, respectively, while the PPV and NPV are $100 \%$ and $88 \%$, respectively. ${ }^{8}$ Therefore, using fetal delta MCA-PSV is likely to identify more twin pregnancies complicated by TAPS antenatally. It remains to be determined whether these proposed diagnostic criteria would lead to better identification of twin pregnancies destined to develop adverse perinatal outcomes. Therefore, the diagnostic criteria outlined in this Delphi consensus should be validated in prospective observational studies before they can be used in clinical trials of interventions. It is important, though, to realise that the postnatal diagnostic criteria of TAPS do not necessitate the finding of an anemic twin and a polycythemic twin at birth, but it identified those with large inter-twin hemoglobin discordance. Similarly, as highlighted in this study, the antenatal diagnostic criteria should ideally include a discordance in MCA PSV and not only be based on a high MCA PSV in the donor and low in the recipient. Almost $50 \%$ of experts agreed on a discordance 0.5 threshold, whereas $33 \%$ opted for a 1.0 threshold. Although the majority of participants would therefore agree that a discordance of at least 1.0MoM would certainly fit with a diagnosis of TAPS, more research is needed to determine the optimal threshold for MCA PSV discordance. The Delphi showed an agreement on the use of antenatal staging 
according to the MCA PSV. Tollenaar et al. have proposed a new antenatal staging system using the delta MCA-PSV instead of the actual MCA PSV values (Supplementary Table 3). ${ }^{8}$

It is very likely that TAPS contributes to the excess fetal loss, and perinatal mortality and morbidity in monochorionic twin pregnancies. This is even more likely when TAPS is not detected prenatally until an advanced stage when one or both twins have developed hydrops or intrauterine demise. However, robust evidence of improved perinatal outcomes when TAPS is diagnosed antenatally does not as yet exist. Nevertheless, this dearth of evidence should not translate into a recommendation by national guidelines not to monitor twin pregnancies for the development of TAPS, in particular in monochorionic twin pregnancies complicated by TTTS and treated by fetoscopic laser, where the development of TAPS and its associated adverse outcomes is well described. ${ }^{18}$

\section{Strengths and limitations}

In order to minimise the potential for peer pressure from authoritative individuals, feedback was provided only at a group level. Rules around acceptance or rejection of parameters were pre-defined, with double-checking of possible interpretation of the answers in subsequent rounds. This enabled the participants to change their minds in light of feedback/group response from previous rounds. The recently published studies proposing new diagnostic criteria including the use of inter-twin MCA PSV discordance were not available at the beginning of the first survey ${ }^{8,9}$, but could have influenced the expert choice in the cut-off threshold, which was determined at the last round.

One of the limitations is the relatively small number of available experts, as TAPS was first described only 10 years ago. It is a specialist area and there is limited knowledge and awareness of its diagnosis and management. Furthermore, only two third of panel members completed all three rounds. Another limitation is the potential for selection bias associated with the inclusion of a group of experts who share similar opinions, which is an inherent weakness of the Delphi methodology. Nevertheless, the experts who agreed to participate were those most familiar with the concepts and clinical implications of TAPS. Finally, this 
study did not address optimal management of TAPS once diagnosed; this would require evidence, ideally in the form of a randomised controlled trial.

\section{Conclusions}

Consensus-based diagnostic criteria for TAPS, as well as the cut-off values for those parameters, were agreed by consensus. Prospective observational studies are needed to validate these diagnostic criteria before they can be used in clinical trials of interventions. 


\section{REFERENCES}

1. Slaghekke F, Kist WJ, Oepkes D, Pasman SA, Middeldorp JM, Klumper FJ, Walther FJ, Vandenbussche FP, Lopriore E. Twin anemia-polycythemia sequence: diagnostic criteria, classification, perinatal management and outcome. Fetal Diagn Ther 2010; 27:181-190.

2. Robyr R, Lewi L, Salomon L.J, Yamamoto, M, Bernard J.-P, Deprest, J, Ville, Y. Prevalence and management of late fetal complications following successful selective laser coagulation of chorionic plate anastomoses in twin-to-twin transfusion syndrome. Am J Obstet Gynecol 2006, 194, 796-803.

3. Lopriore E, Middeldorp, J.M, Oepkes, D, Kanhai H.H, Walther F.J, Vandenbussche F.P.H.A. Twin Anemia-Polycythemia Sequence in Two Monochorionic Twin Pairs Without Oligo-Polyhydramnios Sequence. Placenta 2007, 28, 47-51.

4. Berger $\mathrm{HM}$, de Waard $\mathrm{F}$, Molenaar $\mathrm{Y}$. A case of twin-to-twin transfusion in 1617. Lancet 2000; 356: 847-848.

5. Khalil A, Rodgers M, Baschat A, Bhide A, Gratacos E, Hecher K, Kilby MD, Lewi L, Nicolaides KH, Oepkes D, Raine-Fenning N, Reed K, Salomon LJ, Sotiriadis A, Thilaganathan B, Ville Y. ISUOG Practice Guidelines: role of ultrasound in twin pregnancy. Ultrasound Obstet Gynecol 2016; 47:247-263.

6. Nicholas L.D, Fischbein R.L, Bhamidipalli S.S. Twin anemia-polycythemia sequence and routine monitoring practices amongst maternal-fetal medicine specialists in the United States: an initial investigation. Journal of Perinatal Medicine 2019, 47,388-392.

7. Simpson L.L. Twin-twin transfusion syndrome. Am J Obstet Gynecol 2013, 208, 3-18.

8. Tollenaar LSA, Lopriore E, Middeldorp JM, Haak MC, Klumper FJ, Oepkes D, Slaghekke F. Improved prediction of twin anemia-polycythemia sequence by delta middle cerebral artery peak systolic velocity: new antenatal classification system. Ultrasound Obstet Gynecol 2019; 53:788-793.

9. Tavares de Sousa M, Fonseca A, Hecher K. Role of fetal intertwin difference in middle cerebral artery peak systolic velocity in predicting neonatal twin anemia-polycythemia sequence. Ultrasound Obstet Gynecol 2019; 53:794-797.

10. Hsu CC, Sandford BA. The Delphi Technique: making sense of consensus. Practical Assessment, Research and Evaluation 2007; 12 :1-8.

11. Sinha IP, Smyth RL, Williamson PR. Using the Delphi technique to determine which outcomes to measure in clinical trials: recommendations for the future based on a systematic review of existing studies. PLoS Medicine 2011; 8 : e1000393. 
12. Murphy MK, Black NA, Lamping DL, McKee CM, Sanderson CF, Askham J, Marteau T. Consensus development methods, and their use in clinical guideline development. Health Technol Assess 1998; 2 : 1-88.

13. Kottner J, Audigé L, Brorson S, Donner A, Gajeweski BJ, Hróbjartsson A, Robersts C, Shoukri M, Streiner DL. Guidelines for reporting reliability and agreement studies (GRRAS) were proposed. J Clin Epidemiol 2011; 64 : 96-106.

14. Fishel-Bartal M, Weisz B, Mazaki-Tovi S, Ashwal E, Chayen B, Lipitz S, Yinon Y. Can middle cerebral artery peak systolic velocity predict polycythemia in monochorionic diamniotic twins? Evidence from a prospective cohort study: MCA and polycythemia in MCDA twins. Ultrasound Obstet Gynecol 2016, 48, 470-475.

15. Gucciardo L, Lewi L, Vaast P, Debska M, De Catte L, Van Mieghem T, Done E, Devlieger R, Deprest J. Twin anemia-polycythemia sequence from a prenatal perspective. Prenat Diagn 2010; 30: 438-442.

16. Habli M, Bombrys A, Lewis D, Lim FY, Polzin W, Maxwell R, Crombleholme T. Incidence of complications in twin-twin transfusion syndrome after selective fetoscopic laser photocoagulation: a single-center experience. Am J Obstet Gynecol 2009; 201: 417.e17.

17. Slaghekke F, Lewi L, Middeldorp JM, Weingertner AS, Klumper FJ, Dekoninck P, Devlieger R, Lanna MM, Deprest J, Favre R, Oepkes D, Lopriore E. Residual anastomoses in twin-twin transfusion syndrome after laser: the Solomon randomized trial. Am J Obstet Gynecol 2014; 211: 285.e1-7.

18. Nicholas L, Fischbein R, Aultman J, Ernst-Milner S. Dispelling Myths about Antenatal TAPS: A Call for Action for Routine MCA-PSV Doppler Screening in the United States. J Clin Med 2019; 8(7). 


\section{Figure Legends}

Figure 1. Likert scores of the parameters describing the diagnostic criteria of Twin Anemia Polycythemia Sequence (TAPS). *Dark-thin vs echogenic-thick; ${ }^{\star \star}$ Starry sky vs echogenic.

Figure 2. Likert scores of the parameters to be included in the assessment of Twin Anemia Polycythemia Sequence (TAPS).

Figure 3. Consensus-based diagnostic criteria for Twin Anemia Polycythemia Sequence (TAPS).

Supplementary Figure 1. Likert scores of the parameters to be included in screening for Twin Anemia Polycythemia Sequence (TAPS). *Dark-thin vs echogenic-thick; ${ }^{*}$ Starry sky vs echogenic.

Supplementary Figure 2. Likert scores of the parameters to be included in the monitoring once the diagnosis of Twin Anemia Polycythemia Sequence (TAPS) is made.

Supplementary Figure 3. Likert scores of the parameters to be reported in the postnatal outcome and follow-up of Twin Anemia Polycythemia Sequence (TAPS). 
Table 1 Demographic characteristics of the 50 experts who responded to the survey.

\begin{tabular}{|c|c|}
\hline Details of expert panel & $\begin{array}{l}\text { Number } \\
\text { (\%) }\end{array}$ \\
\hline \multicolumn{2}{|l|}{ Region of practice } \\
\hline Europe & $17(34)$ \\
\hline North America & $22(44)$ \\
\hline South America & $1(2)$ \\
\hline Asia / Australia & $10(20)$ \\
\hline Africa & 0 \\
\hline \multicolumn{2}{|l|}{ Level of care } \\
\hline General / routine obstetric centre & 0 \\
\hline Fetal medicine center offering prenatal diagnosis but no fetal therapy & $4(8)$ \\
\hline Fetal medicine center offering prenatal diagnosis and fetal therapy & $46(92)$ \\
\hline \multicolumn{2}{|l|}{ Number of monochorionic twins deliveries at expert's hospital* } \\
\hline$<20$ & $3(6)$ \\
\hline $20-30$ & $12(24)$ \\
\hline $30-40$ & $6(12)$ \\
\hline $40-50$ & $8(16)$ \\
\hline$>50$ & $21(42)$ \\
\hline Unknown & 0 \\
\hline \multicolumn{2}{|l|}{ Number of dichorionic twins deliveries at expert's hospita/* } \\
\hline$<50$ & $5(10)$ \\
\hline $50-100$ & $16(32)$ \\
\hline $100-150$ & $9(18)$ \\
\hline $150-200$ & $13(26)$ \\
\hline$>200$ & $7(14)$ \\
\hline Unknown & 0 \\
\hline \multicolumn{2}{|l|}{ Invasive procedures performed at expert's hospital } \\
\hline Amniocentesis & $50(100)$ \\
\hline Embryo and fetal reduction in multiple pregnancies & $45(90)$ \\
\hline Chorionic villus sampling & $49(98)$ \\
\hline Fetoscopic laser photocoagulation & $38(76)$ \\
\hline Bipolar cord occlusion & $36(72)$ \\
\hline Interstitial radio-frequency / laser ablation & $40(80)$ \\
\hline Other** & $16(32)$ \\
\hline
\end{tabular}

* On annual base

** Cardiac balloon procedures, Myelomeningocele repair, intrauterine transfusion, shunting, fetal cardiac interventions, open fetal myelomeningocele repair, drainage of fetal fluid collections, fetal cystoscopy, Fetoscopic endoluminal tracheal occlusion (FETO), fetal endoscopic tracheal intubation (FETI), cordocentesis, shunt for pleural effusion, embolization of chorioangioma, balloon valvoplasty, microwave ablation, open fetal surgery. 
Table 2. Agreed parameters for the definition, screening and monitoring and outcome of twin pregnancies complicated by twin anemia polycythemia sequence (TAPS).

\begin{tabular}{|c|c|}
\hline List of parameters & $\begin{array}{l}\text { Voting by the } \\
\text { expert panel } \\
\text { (\% in favor) }\end{array}$ \\
\hline \multicolumn{2}{|l|}{ Diagnostic criteria } \\
\hline Middle cerebral artery (MCA) peak systolic velocity (PSV) & 100 \\
\hline MCA PSV discordance & 97 \\
\hline \multicolumn{2}{|l|}{ Screening } \\
\hline MCA PSV & 100 \\
\hline MCA PSV discordance & 97 \\
\hline \multicolumn{2}{|l|}{ Monitoring once the diagnosis is made } \\
\hline Fetal Doppler & 100 \\
\hline Fetal hydrops & 97 \\
\hline \multicolumn{2}{|l|}{ Monitoring } \\
\hline MCA PSV discordance & 95 \\
\hline Evidence of cardiac compromise & 97 \\
\hline Fetal hydrops & 100 \\
\hline Gestational age at assessment & 100 \\
\hline Gestational age at first diagnosis & 86 \\
\hline MCA PSV of the anemic twin & 100 \\
\hline MCA PSV of the polycythemic twin & 100 \\
\hline \multicolumn{2}{|l|}{ Pregnancy outcome and postnatal follow-up } \\
\hline Brain abnormalities on ultrasound or MRI & 100 \\
\hline Gestational age at birth & 100 \\
\hline Hemoglobin level & 100 \\
\hline Limb thrombosis & 95 \\
\hline Long-term assessment of the twins & 100 \\
\hline Need for transfusion/exchange transfusion & 100 \\
\hline Reticulocyte count & 95 \\
\hline
\end{tabular}




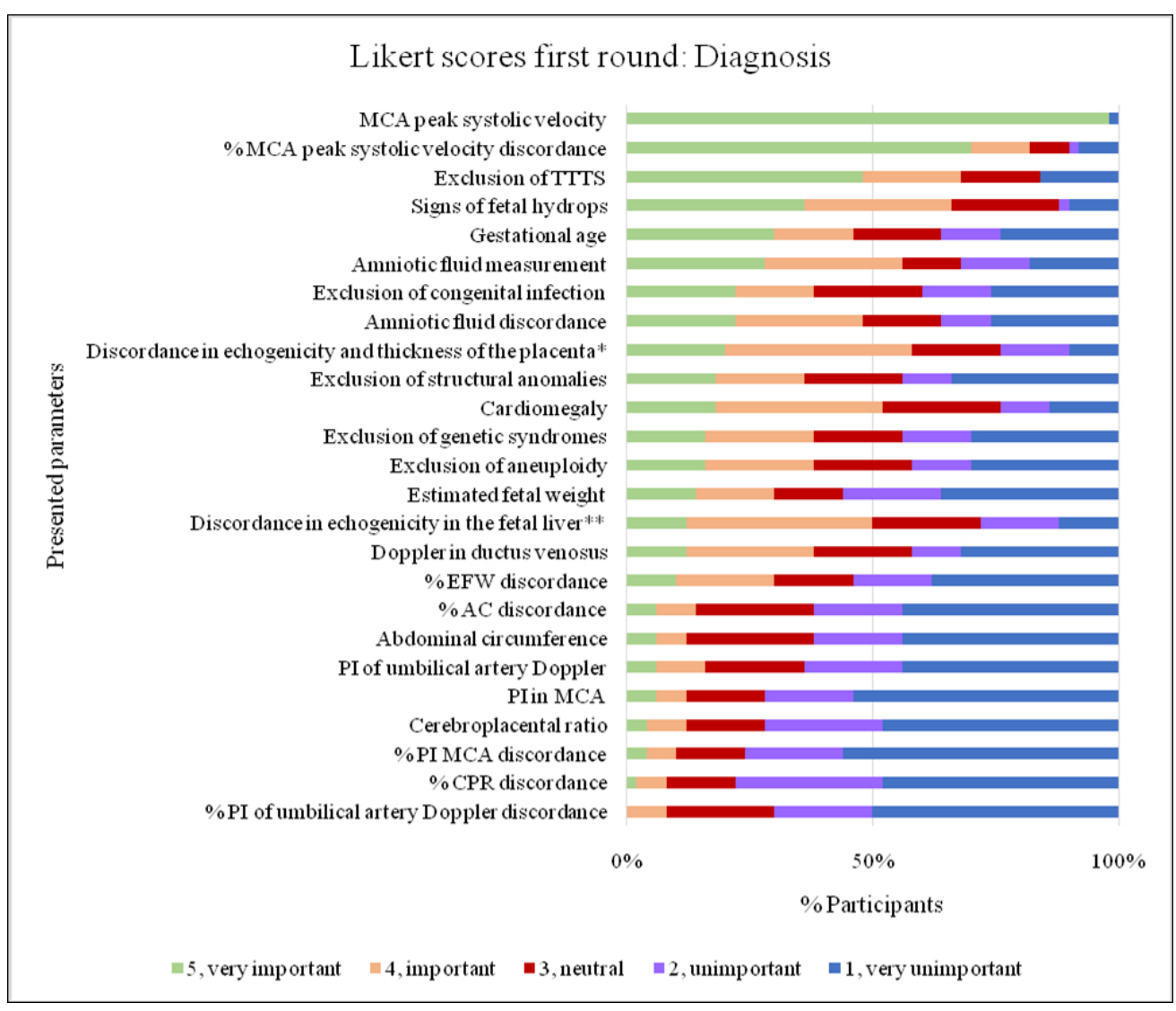




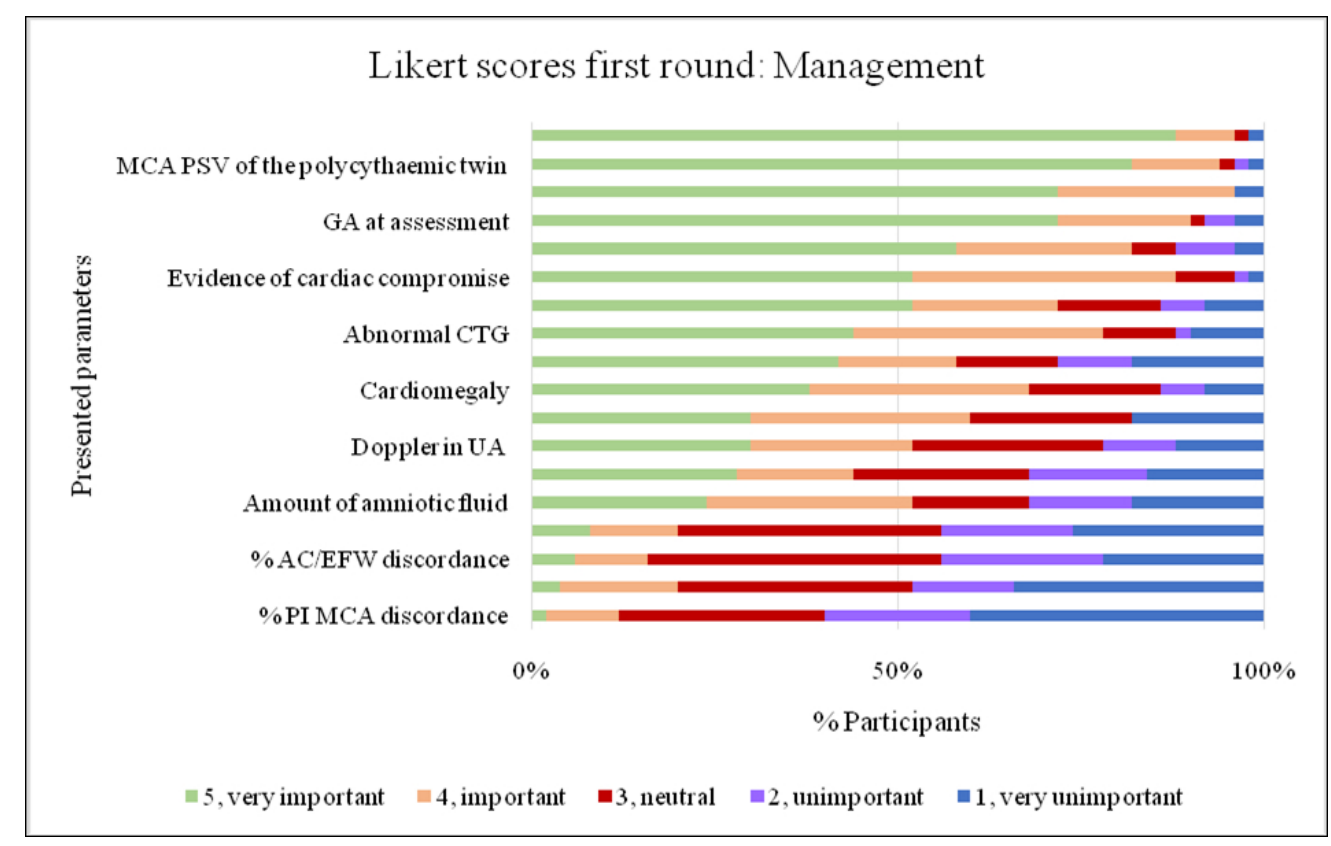

This article is protected by copyright. All rights reserved. 


\section{Diagnostic criteria of Twin Anemia Polycythemia Sequence}

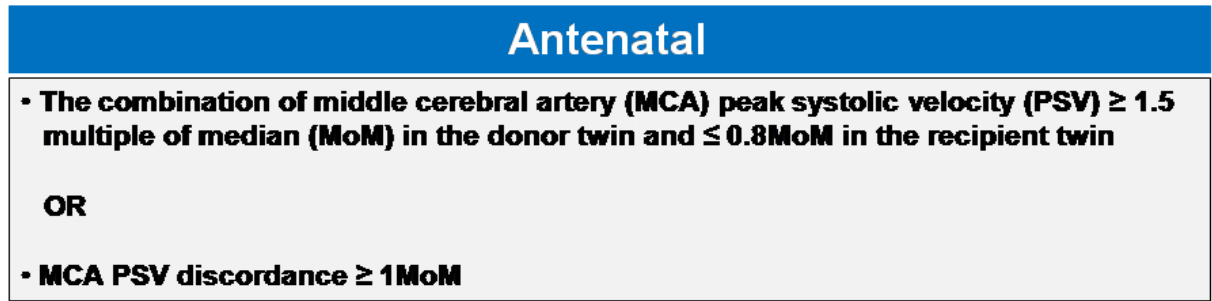

\section{Postnatal}

- Inter-twin hemoglobin difference $\geq 8$ g/dL

AND

- Inter-twin reticulocyte ratio $\geq 1.7$

Figure 3 